\title{
EDITORIAL
}

\section{Asthma, COPD and bronchitis are just components of airway disease}

\author{
F.E. Hargreave and K. Parameswaran
}

D iseases of the airways of the lungs are common and include asthma, chronic obstructive pulmonary disease (COPD) and bronchitis, as well as emphysema and bronchiectasis. Their diagnosis is often inaccurate because appropriate measurements are not made [1-3] and the definition of airway disease is still imprecise. For example, the Global Initiative for Asthma (GINA) definition of asthma describes components but fails to give a primary definition which distinguishes the disease from others [4]. The Canadian definition of COPD includes partly reversible airflow limitation, which is what many would define as asthma [5]. Therefore, it seems appropriate to reconsider how we diagnose and define airway disease; this is important in order to optimise treatment.

\section{COMPONENTS OF AIRWAY DISEASES}

The components (characteristics, features, etc.) of airway disease include symptoms, variable airflow limitation, airway hyperresponsiveness, chronic airflow limitation and airway inflammation, as well as emphysema and bronchiectasis (fig. 1). They can exist in various combinations. Airway inflammation is central to all other components. It is a cause of symptoms, variable airflow limitation through release of bronchoconstrictor mediators, and chronic airflow limitation through remodelling with structural changes. It also increases airway responsiveness. These components correlate poorly with one another [6-9]. The best correlation is between the diurnal variation of peak expiratory flow (PEF) and airway responsiveness [10], which is not surprising since the latter is an important determinant of the former. Symptoms of chest tightness, wheezing, dyspnoea, cough and sputum are all nonspecific since they can result from each of the other components, as well as other respiratory and nonrespiratory conditions. Hence, measurements are needed to be certain as to what the symptoms are associated with.

\section{MEASUREMENTS IN AIRWAY DISEASES}

The following measurements are widely available: 1) spirometry with the effect of an inhaled $\beta$-agonist to measure

Firestone Institute for Respiratory Health, St Joseph's Healthcare \& Dept of Medicine, McMaster University, Hamilton, ON, Canada.

CORRESPONDENCE: F.E. Hargreave, Firestone Institute for Respiratory Health, St Joseph's Healthcare, 50 Charlton Avenue East, Hamilton, ON, L8N 4A6, Canada. Fax: 1 9055216158. E-mail: hargreav@mcmaster.ca

SUPPORT STATEMENT: K. Parameswaran is supported by a Canada Research Chair in Airway Inflammation. reversibility; 2) PEF, especially to measure diurnal variation of airflow limitation; 3 ) post- $\beta$-agonist spirometry for chronic airflow limitation; and 4) methacholine (or indirect stimuli) tests to measure airway responsiveness (fig. 2). More recently, quantitative spontaneous or induced sputum cell counts and exhaled nitric oxide (NO) have been introduced to measure airway inflammation, although they are not yet widely available [11, 12].

Sputum cell counts provide the most comprehensive and valid clinical measurement of airway inflammation as they specifically identify different types of inflammation that are a result of different causes and mechanisms and which result in different pathophysiology [13]. The types and causes are as follows: 1) eosinophilic, resulting from sensitisation and reactions to inhaled allergens or occupational chemical sensitisers, reduction of corticosteroid treatment, or unknown; 2) neutrophilic, due to viral or bacterial infections, cigarette smoke, cystic fibrosis, $\alpha_{1}$-antitrypsin deficiency, or atmospheric or occupational exposures; or 3) both eosinophilic and neutrophilic, or neither. Most of these causes are common, one or more may be present at the same time and these may vary from one time to another. Therefore, it is to be expected that airway disease will commonly be heterogeneous.

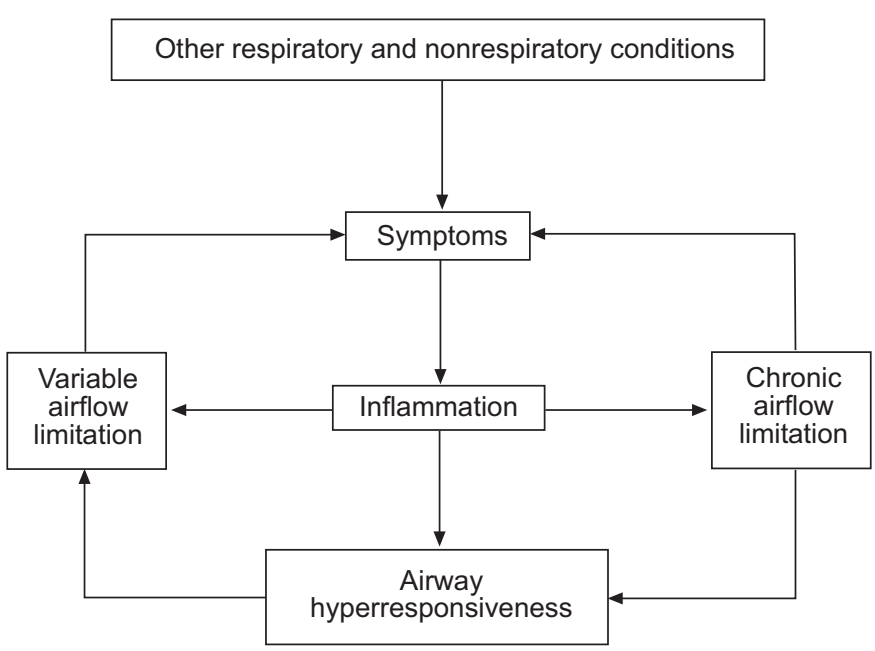

FIGURE 1. Relationships between components of airway diseases. Airway inflammation influences all other components, including emphysema and bronchiectasis, which are not shown. Airway hyperresponsiveness is an important determinant of variable airflow limitation and is itself also influenced by the presence of airflow limitation. 


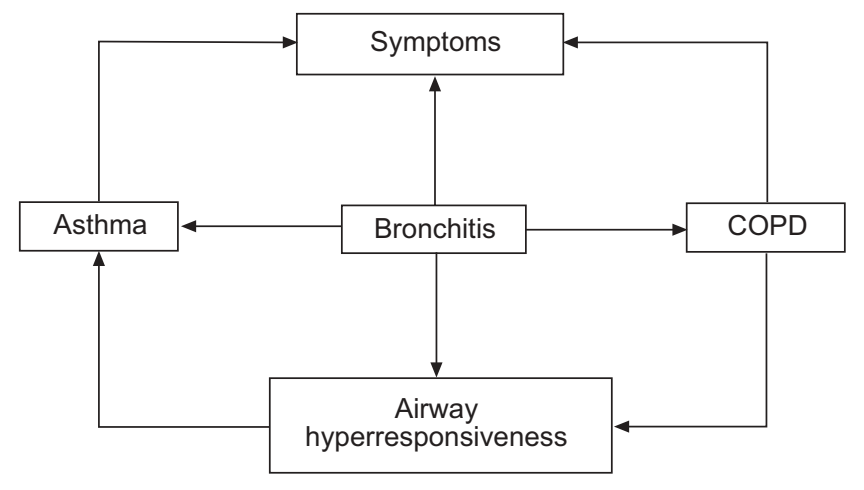

FIGURE 2. Diseases' equal components (see fig. 1). Asthma is variable airflow limitation, chronic obstructive pulmonary disease (COPD) is chronic airflow limitation and bronchitis or bronchiolitis is airway inflammation.

Exhaled NO, while it increases with eosinophilic inflammation, is not specific for eosinophilia and is unable to reliably identify noneosinophilic inflammation, which is a common cause of exacerbations. Nonetheless, its use in clinical practice can be an advantage over only using symptoms and spirometry to guide corticosteroid treatment $[12,14]$, but is not as effective or discriminative as the use of sputum cell counts [11, 15].

\section{DEFINITIONS AND DISEASES}

Between 1959 and 1971, a number of working groups sought to define asthma, COPD, emphysema and chronic bronchitis [1619]. SCADDING [20] highlighted that there needs to be a primary defining characteristic, which may be of several different sorts, depending upon the point that has been reached in a diagnostic process, which moves towards but frequently stops short of causation, its desirable end-point. The simplest definition of a disease is based on symptoms or signs and is known as a syndrome, e.g. as with a common cold. The best primary definition of a disease is based on a cause, e.g. tuberculosis. In between, definitions can be based on a unifying abnormality of function or of pathology.

Hence, if we consider asthma, the definition cannot be based on symptoms or signs because, as stated previously, these are not specific. Neither can it be based on a cause because there are several causes, e.g. hypersensitivity to inhaled allergens or viral infections or unknown. Furthermore, it cannot be based on pathology because, at least with current understanding, there is not a unifying pathology. Therefore, ScADDING [20] proposed that asthma be defined by an abnormality of function as "a disease characterised by wide variations over short periods of time in resistance to flow in intrapulmonary airways", and this is widely accepted. The wide variations in resistance to flow are objectively validated by improvement in forced expiratory volume in one second (FEV1) after inhaled rapid-acting $\beta$-agonist, by an increase in the diurnal variability of PEF (which best incorporates the effect of a rapid-acting $\beta$ agonist [10]), or, especially when the FEV1 is normal, by an increased tendency for the FEV1 to fall after a bronchoconstrictive stimulus (i.e. airway hyperresponsiveness).

In a similar way to asthma, COPD has also been defined, and still is, as an abnormality of airway function as a "disease state characterised by airflow obstruction that is not fully reversible" [21]. Like asthma, this cannot be primarily defined by pathology or cause. While cigarette smoking is a common cause, COPD can occur in nonsmokers. It can be associated with different kinds of airway inflammation of different causes, e.g. eosinophilic inflammation [22] or neutrophilic inflammation due to infection [23]. It can also be associated with asthma as defined by an abnormality of function [24].

The other component of asthma or COPD is airway inflammation. This is bronchitis or bronchiolitis which can also, and commonly does, occur without asthma or COPD. As such, bronchitis is a disease that can be clinically validated by quantitative sputum cell counts.

When considered in this way, the diseases asthma and COPD are just physiological components of airway disease and bronchitis is the inflammatory component (fig. 2). A patient with asthma may or may not have an eosinophilic bronchitis and, in a nonsmoker, as well as a smoker, may or may not develop COPD. The smoker with COPD may have an eosinophilic bronchitis or asthma. A neutrophilic bronchitis due to infection can occur in any situation. Hence, the diseases are not necessarily mutually exclusive; combinations commonly occur and can vary from one patient to another. Their recognition is important to rationalise and optimise minimum treatment to achieve the best results with the least side-effects and cost.

\section{TREATMENT}

The treatment of airway disease is determined by the disease(s) present and its (their) severity. The asthma component is treated with bronchodilators of which the most effective is the $\beta$-agonist. If this is associated with eosinophilic bronchitis, which can increase variable airflow limitation (including airway hyperresponsiveness), it will also respond to corticosteroid treatment [25] or treatment of its cause. Eosinophilic bronchitis with COPD $[22,24,26]$ or an isolated chronic cough [27] will also be expected to respond to these measures. Bacterial infective neutrophilic bronchitis benefits from treatment with an antibiotic. So far, viral noneosinophilic, usually neutrophilic [28, 29], bronchitis resolves spontaneously and requires only palliative treatment of any exacerbation of asthma. There is no effective treatment of COPD without eosinophilia other than limited and transient benefit from anticholinergic treatment in some, avoidance of causal factors and treatment of complications.

The severity of asthma is the magnitude of variable airflow limitation. The severity of COPD is the degree of chronic airflow limitation. The severity of eosinophilic bronchitis is reflected by the percentage of sputum eosinophils and the minimum dose of corticosteroid required to control it. Of course, eosinophilic bronchitis can also determine the severity of airflow limitation and variable airflow limitation, which can be reduced by controlling it. The poor correlation between the presence and severity of variable airflow limitation and eosinophilic bronchitis means that asthma may be absent or mild when eosinophilic bronchitis is severe, or vice versa. A patient with severe eosinophilic bronchitis might need maintenance prednisone treatment but no regular bronchodilator. A patient with a severe increase in airway responsiveness and variable airflow limitation may require daily long-acting $\beta$ agonist, but little or no corticosteroid. 


\section{CONCLUSION}

There is widespread difference in opinion about the meaning of asthma, which is due to a failure to appreciate that the primary definition must be based on an abnormality of function that distinguishes it from other diseases. Other components of the disease, such as airway inflammation and chronic airflow limitation, may also be present but these can occur without asthma and so are not defining characteristics. The airway inflammation and chronic airflow limitation components also define the diseases of bronchitis and COPD. Hence, the components are the diseases present. None of them are mutually exclusive and they commonly occur together. Their recognition through measurement rationalises and helps to optimise minimum treatment.

This point of view supports the Dutch hypothesis that was put forward in the 1960s by ORIE et al. [30] and reviewed recently by Postma and BoEzen [31]. This suggested that the various types of airway diseases should not be considered as separate diseases but as one disease entity, the components of which are influenced by host (genetic) and environmental factors. Clinical evaluation should be of the components and causes in order to rationalise, individualise and optimise treatment. We agree, but propose that the names asthma, chronic obstructive disease and bronchitis are retained for what they are, components of airway disease.

\section{ACKNOWLEDGEMENTS}

The authors would like to thank D. Lawson for preparing the article. The authors dedicate this article to the memory of both E.J. Moran Campbell (who wanted it written during his lifetime) and R. Smith-Blackwell (who also prepared the figures).

\section{REFERENCES}

1 LindenSmith J, Morrison D, Deveau C, Hernandez P. Overdiagnosis of asthma in the community. Can Respir J 2004; 11: 111-116.

2 Renwick DS, Connolly MJ. Prevalence and treatment of chronic airways obstruction in adults over the age of 45 . Thorax 1996; 51: 164-168.

3 Parameswaran K, Pizzichini E, Pizzichini MMM, Hussack P, Efthimiadis A, Hargreave FE. Clinical judgement of airway inflammation versus sputum cell counts in patients with asthma. Eur Respir J 2000; 15: 486-490.

4 Global Initiative for Asthma. Global strategy for asthma management and prevention NHLBI/WHO workshop report. NIH Publication Number 02-3659. Bethesda, National Institute of Health, National Heart, Lung and Blood Institute, 2004.

5 O'Donnell DE, Aaron S, Bourbeau J, et al. State of the art compendium: Canadian Thoracic Society recommendations for the management of chronic obstructive pulmonary disease. Can Respir J 2004; 11: Suppl. B, 7B-59B.

6 van den Berge M, Meijer RJ, Kerstjens HAM, et al. PC20 adenosine $5^{\prime}$-monophosphate is more closely associated with airway inflammation in asthma than PC20 methacholine. Am J Respir Crit Care Med 2001; 163: 1546-1550.

7 Haley KJ, Drazen JM. Inflammation and airway function in asthma: what you see is not necessarily what you get. Am J Respir Crit Care Med 1998; 157: 1-3.
8 Rosi E, Ronchi MC, Grazzini M, Duranti R, Scano G. Sputum analysis, bronchial hyperresponsiveness and airway function in asthma: results of a factor analysis. $J$ Allergy Clin Immunol 1999; 103: 232-237.

9 Lapperre TS, Snoeck-Stroband JB, Gosman MME, et al. Dissociation of lung function and airway inflammation in chronic obstructive pulmonary disease. Am J Respir Crit Care Med 2004; 170: 499-504.

10 Ryan G, Latimer KM, Dolovich J, Hargreave FE. Bronchial responsiveness to histamine: relationship to diurnal variation of peak flow rate, improvement after bronchodilator and airway calibre. Thorax 1982; 37: 423-429.

11 Jayaram L, Pizzichini MM, Cook RJ, et al. Determining asthma treatment by monitoring sputum cell counts: effect on exacerbations. Eur Respir J 2006; 27: 483-494.

12 Smith AD, Cowan JO, Brassett KP, Herbison PG, Taylor DR. Use of exhaled nitric oxide measurements to guide treatment in chronic asthma. N Engl J Med 2005; 352: 2163-2173.

13 Simpson JI, Scott R, Boyle MJ, Gibson PG. Inflammatory subtypes in asthma: assessment and identification using induced sputum. Respirology 2006; 11: 54-61.

14 Pijnenburg MW, Bakker EM, Hop WC, De Jongste JC. Titrating steroids on exhaled nitric oxide in children with asthma: a randomized controlled trial. Am J Respir Crit Care Med 2005; 172: 831-836.

15 Green RH, Brightling CE, McKenna S, et al. Asthma exacerbations and sputum eosinophil counts: a randomized controlled trial. Lancet 2002; 360: 1715-1721.

16 Porter R, Birch J, eds. Identification of asthma. Ciba Foundation Study Group no. 38. Edinburgh and London, Churchill Livingstone, 1971.

17 American Thoracic Society. Definitions and classification of chronic bronchitis, asthma and pulmonary emphysema. Am Rev Respir Dis 1962; 85: 762-768.

18 Definition and classification of chronic bronchitis for clinical and epidemiological purposes. A report to the Medical Research Council by their Committee on the Aetiology of Chronic Bronchitis. Lancet 1965; 1: 775-779.

19 Ciba Foundation Guest Symposium. Terminology, definitions and classification of chronic pulmonary emphysema and related conditions. Thorax 1959; 14: 286-299.

20 Scadding JG. Definition and clinical categories of asthma. In: Clark TJH, Godfrey S, eds. Asthma. London, Chapman and Hall Ltd, 1983; pp. 1-11.

21 Global Initiative for Chronic Obstructive Pulmonary Disease. Global Strategy for the diagnosis and management and prevention of COPD. Bethesda, NHLBI/WHO Workshop Report 2005.

22 Pizzichini E, Pizzichini MMM, Gibson PG, et al. Sputum eosinophilia predicts benefit from prednisone in smokers with chronic obstructive bronchitis. Am J Respir Crit Care Med 1998; 158: 1511-1517.

23 Hurst JR, Perera WR, Wilkinson TMA, Donaldson GC, Wedzicha JA. Systemic and upper and lower airway inflammation at exacerbation of chronic obstructive pulmonary disease. Am J Respir Crit Care Med 2006; 173: 71-78.

24 Leigh R, Pizzichini MM, Morris MM, Maltais F, Hargreave FE, Pizzichini E. Stable COPD: predicting benefit from high-dose inhaled corticosteroid treatment. Eur Respir J 2006; 27: 964-971. 
25 Pavord ID, Brightling CE, Woltmann G, Wardlaw AJ. Noneosinophilic corticosteroid unresponsive asthma. Lancet 1999; 353: 2213-2214.

26 Brightling CE, Monteiro W, Ward R, et al. Sputum eosinophilia and short-term response to prednisolone in chronic obstructive pulmonary disease: a randomized controlled trial. Lancet 2000; 356: 1480-1485.

27 Gibson PG, Dolovich J, Denburg J, Ramsdale EH, Hargreave FE. Chronic cough: eosinophilic bronchitis without asthma. Lancet 1989; 1: 1346-1348.

28 Pizzichini MMM, Pizzichini E, Efthimiadis A, et al. Asthma and natural colds. Inflammatory indices in induced sputum; a feasibility study. Am J Respir Crit Care Med 1998; 158: 1178-1184.

29 Wark PAB, Johnston SL, Moric I, Simpson JL, Hensley MJ, Gibson PG. Neutrophil degranulation and cell lysis is associated with clinic severity in virus-induced asthma. Eur Respir J 2002; 19: 68-75.

30 Orie NGM, Sluiter JH, eds. Bronchitis II: Second International Symposium. Assen, Royal Van Gorcum, 1964.

31 Postma DS, Boezen HM. Rationale for the Dutch hypothesis. Allergy and airway hyperresponsiveness as genetic factors and their interaction with environment in the development of asthma and COPD. Chest 2004; 126: Suppl. 2, 96s-104s. 